\title{
Research from the South
}

\section{Detecting bacteriuria in a primary maternal and child health care programme}

\author{
K S JOSEPH, K N BRAHMADATHAN, SULOCHANA ABRAHAM, ABRAHAM JOSEPH
}

\begin{abstract}
Urinary tract infection in pregnancy has not been adequately dealt with in developing countries, though its consequences are well recognised. This is primarily because of constraints on resources coupled with a lack of technological infrastructure. An evaluation of the Griess test for the mass screening of urinary tract infection among antenatal women was carried out prospectively using a case-control method.

The Griess test was found to be a valid, reliable, and economical screening test for urinary tract infection which can be integrated into a primary maternal and child health care programme.
\end{abstract}

\section{Introduction}

The rapid advancements in medicine may be set against the practice of medicine in the less developed countries. The lack of technological infrastructure and prohibitive costs force less developed countries to forego the benefits of the latest scientific research. Urinary tract infection in pregnancy is one example. Urinary tract infection is one of the most common medical complications of pregnancy and occurs in $2 \%$ to $20 \%$ of pregnant women. ${ }^{1.5}$ It is especially important in pregnancy because acute pyelonephritis develops in $30 \%$ of women whose bacteriuria is not treated. ${ }^{6}$

Acute pyelonephritis is a serious illness with fever and greatly affects both the mother and the fetus. Also there is evidence that even when there are no symptoms untreated bacteriuria in pregnancy may lead to a less favourable fetal outcome. ${ }^{6}$ Despite this, detecting asymptomatic bacteriuria in pregnant women by urine culture or microscopy has not become a routine part of antenatal care in developing countries. This is primarily because of a shortage of skilled health workers or the cost, or both. Therefore attention needs to be concentrated on more appropriate technology. The Griess test is an example of this. Described by others as a simple, cheap, and effective test, it can be used in the mass screening of pregnant women for urinary tract infection. ${ }^{78}$ At a low cost and using available resources it can help to reduce the morbidity and

\footnotetext{
Department of Community Health, Christian Medical College and Hospital, Vellore, South India

K S JOSEPH, MD, research officer

SULOCHANA ABRAHAM, MD, MPH, associate professor

ABRAHAM JOSEPH, MD, MS, professor and head

Department of Microbiology

K N BRAHMADATHAN, PHD, senior lecturer

Correspondence to: Dr K S Joseph.
}

mortality from clinically detectable bacteriuria among pregnant women.

We report a study on the use of the Griess test.

\section{Methods}

The Griess reagent was prepared by dissolving $1.5 \mathrm{~g}$ of chemically pure sulphanilic acid in $450 \mathrm{ml}$ of $10 \%$ acetic acid. This was then added to a solution of $0.6 \mathrm{~g} \alpha$ naphthylamine dissolved in boiling distilled water. The reagent was stored in an amber bottle and refrigerated. Deterioration of the colourless reagent was detected by the development of a pink colour. Urine was tested by adding $1.0 \mathrm{ml}$ of an early morning sample of urine to $1.0 \mathrm{ml}$ of the reagent in a clean test tube. The immediate development of a pink to dark red colour was taken to show the presence of nitrites and hence the presence of appreciable coliform infection.

The patients who receive antenatal care at the Community Health and Development hospital and its 40 clinics comprised the study group. The Community Health and Development project is a primary health care programme for a population of 80000 in a rural area of south India. Each patient was given a clean bottle and asked to collect a clean early morning specimen of urine. The urine was tested in the field or base hospital with the Griess reagent according to the prescribed procedure. ${ }^{7}$ This was done as quickly after collection as possible since it was not possible to refrigerate these urine samples. All patients whose urine was positive by the Griess test were designated as cases, and routine urine cultures were done. Three controls were chosen from the population whose results were negative for each case diagnosed after matching as closely as possible for age and parity. Their urine samples were also cultured.

As part of a study to ascertain whether the Griess test could be integrated into the existing primary health care for maternal and child health in the area 10 community health workers were instructed in carrying out the test. They were subsequently required to test 20 different samples of urine (three of which were positive) and declare them to be either positive or negative.

The cost of the Griess reagent was calculated from the cost of various chemical constituents and computed at Rs $0 \cdot 10$ (less than $1 \mathrm{p}$ per test). Ten times this cost was used for comparison, and the increase was meant to cover overhead costs. The cost of diagnosing one case of clinically relevant bacteriuria among pregnant women was calculated and compared with the cost of routine screening and diagnosis of other conditions in pregnancy. The data for these comparisons were obtained retrospectively from the antenatal records of patients, which were kept at this hospital and at the Christian Medical College Hospital.

Quantification of urine cultures was carried out using the calibrated loop technique in the microbiology department.9 Patients were repeatedly instructed on how to collect a clean midstream sample of urine and the procedure was supervised. Specimens for culture were packed in ice and sent to the laboratory, where they were immediately plated according to the standard procedure.

\section{Results}

A total of 697 pregnant women were tested with the Griess reagent, and 19 were found to be positive. This yields a prevalence of $2.7 \%$ with a $95 \%$ confidence interval of $1.5 \%$ to $3.9 \%$. Of these 19 patients, 11 had colony counts of over $100000 / \mathrm{ml}$. One patient's urine culture showed a pure growth 
of Escherichia coli with a colony count of $7500 / \mathrm{ml}$. A repeat urine culture for the same patient five days later showed $E$ coli again and a colony count of $15000 / \mathrm{ml}$. This patient was considered to have significant bacteriuria because of an appreciable increase in the colony count. Another patient's urine grew $E$ coli with a colony count of $24500 / \mathrm{ml}$, but a repeat culture could not be obtained as she went into labour before the culture results were known. As the colony count was under $100000 / \mathrm{ml}$ this patient was included in the group whose culture showed clinically unimportant colony counts. The remaining six patients had either no growth or clinically unimportant bacteriuria.

For all 57 control patients urine cultures showed either no growth or clinically unimportant bacteriuria with colony counts of under $1000 / \mathrm{ml}$.

The two by two format in table I gives the results of the validity assessment. No false negative cases were identified, and the number of false positives was also reasonably low. All 10 community health workers were able to identify the 20 urine samples correctly as negative or positive.

TABLE I-Validity of the Griess test as a screening test for significant bacteriuria

\begin{tabular}{lccc}
\hline & \multicolumn{3}{c}{ No of urine cultures showing bacteriuria: } \\
\cline { 2 - 4 } & Significant & $\begin{array}{c}\text { Not } \\
\text { significant }\end{array}$ & $\begin{array}{c}\text { Total } \\
\text { No }\end{array}$ \\
\hline Griess test: & 12 & 7 & 19 \\
Positive & 0 & 57 & 57 \\
Negative & 12 & 64 & 76 \\
\hline Total & & & \\
\hline
\end{tabular}

TABLE II-Cost of diagnosing various clinical conditions in pregnancy

\begin{tabular}{|c|c|c|c|c|c|c|}
\hline \multirow[b]{2}{*}{ Condition } & \multirow{2}{*}{$\begin{array}{l}\text { No of } \\
\text { patients }\end{array}$} & \multirow{2}{*}{$\begin{array}{c}\text { Prevalence } \\
(\%)\end{array}$} & \multicolumn{2}{|c|}{ Cost per test } & \multicolumn{2}{|c|}{$\begin{array}{c}\text { Cost per case } \\
\text { diagnosed }\end{array}$} \\
\hline & & & Rs & $£$ & Rs & $£$ \\
\hline $\begin{array}{l}\text { Anaemia } \\
\text { (Sahli's method) } \\
\text { Syphilis }\end{array}$ & 425 & 25 & $2 /-$ & $0 \cdot 10$ & $8 /-$ & $0 \cdot 40$ \\
\hline $\begin{array}{l}\text { (VRDL) } \\
\text { Rh negative }\end{array}$ & 580 & $2 \cdot 1$ & $20 /-$ & $1 \cdot 00$ & $967 /-$ & $48 \cdot 35$ \\
\hline $\begin{array}{l}\text { blood typing } \\
\text { Pronounced }\end{array}$ & 552 & $5 \cdot 6$ & $28 /-$ & $1 \cdot 36$ & $449 /-$ & $21 \cdot 81$ \\
\hline $\begin{array}{c}\text { bacteriuria } \\
\text { (Griess test) } \\
\text { Significant } \\
\text { bacteriuria }\end{array}$ & 697 & $2 \cdot 7$ & $1 /-$ & 0.05 & $37 /-$ & 1.85 \\
\hline $\begin{array}{l}\text { (Griess test }+ \\
\text { urine culture on positives) }\end{array}$ & 697 & $1 \cdot 7$ & $\begin{array}{r}1 /- \\
35 /-\end{array}$ & $\begin{array}{l}0.05 \\
1 \cdot 70\end{array}$ & $114 /-$ & $5 \cdot 70$ \\
\hline bacteriuria (urine culture) & - & $1 \cdot 7$ & $35 /-$ & $1 \cdot 70$ & 2059/- & 102.95 \\
\hline
\end{tabular}

The prevalence of significant bacteriuria was $1 \cdot 7 \%$. The most frequent pathogen isolated was $E$ coli (nine cultures) followed by Klebsiella sp (two), and Enterobacter sp (one). The sensitivity pattern showed that 11 of 12 pathogens were sensitive to nitrofurantoin, seven of 12 to co-trimoxazole, and four of 12 to ampicillin.

The cost of various tests used to diagnose urinary tract infection is as follows: urine microscopy $15 p$ (Rs 3-00), urine Gram stain $15 p$ (Rs 3-00), urine culture $£ 1 \cdot 70$ (Rs $35-00$ ), the Griess test 5 p (Rs 1-00). Although the tests yield differing information of varying quality and hence are not strictly comparable, nevertheless the Griess test compares favourably with the others in cost. Table II gives the costs of diagnosing various clinical conditions in pregnancy. The Griess test appears to be an affordable alternative to culture methods for diagnosing urinary tract infection.

\section{Discussion}

Our assessment of the validity of the Griess test to screen for urinary tract infection confirmed the findings of others ${ }^{78}$ that it is a sensitive and specific test for coliform bacilluria. Although the Griess test does not detect some organisms-notably enterococci, some staphylococci, and some Pseudomonas aeruginosa-this does not affect the validity of the test as these pathogens do not contribute greatly to urinary tract infection.

The predictive values follow the expected pattern for a disease of low prevalence. ${ }^{10}$ More can be said regarding the value of a negative test compared with a positive test. Some of the false positive results may have occurred because of occasional delays in testing urine samples as these could not be stored on ice. The study to assess the feasibility of integrating the Griess test into the primary health care for maternal and child health showed that community health workers could be easily trained to perform the test. (Though illiterate, community health workers have been trained to perform simple tests such as testing for urine albumin and sugar.) A minor problem during training was a tendency to obtain a small number of false positives, which occurred because the test tube was not washed thoroughly after testing a positive sample. This was easily corrected with repeated instruction.

The low prevalence of significant bacteriuria found in this study is surprising given how common the factors that are known to increase prevalence are, including increasing age, parity, low socioeconomic state, few medical facilities, and frequency of sexual intercourse. Because of the methods used in the study the prevalence figure can be looked upon only as an approximation. Nevertheless the finding of a low prevalence of asymptomatic bacteriuria seems to corroborate an observation (unpublished) made by clinicians that acute pyelonephritis occurs far less frequently in this area compared with that reported from elsewhere.

The calculation of costs shows that the Griess test is well suited for its purpose, especially where resources are scarce. When community health workers perform the test the costs are further reduced.

The Griess test-a simple reaction which gives a dramatic and not unpleasing colour when positive-did not evoke negative responses from patients or health workers. Antenatal patients, who are used to giving samples of urine for sugar and albumin testing, did not find collecting an early morning specimen of urine unacceptable. The sensitivity pattern of the pathogens that were isolated showed an almost uniform susceptibility to nitrofurantoin. This drug is available and reasonably cheap. Thus the Griess test satisfies the requirements of a screening test for bacteriuria ${ }^{11}$ and can be integrated into a primary maternal and child health care programme.

This study was carried out with funds from the Epidemiology Resource Centre, Christian Medical College and Hospital, Vellore. We thank Ms Manjula, Ms Gomathy, and Mr David Selvapandian for their help.

\section{References}

1 Wait RB. Urinary tract infection during pregnancy. Asymptomatic bacteriuria, acute cystitis and acute pyelonephritis. Postgrad Med 1984;75:153-7,161.

2 Harris R. Urinary tract infection during pregnancy. In: Buchsbaum HJ, Sciarra JJ, eds. Gynecology and obstetrics. Philadelphia: Harper and Row, 1984

3 Whalley P. Bacteriuria of pregnancy. Am f Obstet Gynecol 1967;97:723-38.

4 Urrutia J, Sora R, Kennel J, Klaus M. Prevalence of maternal and neonatal infections in a developing country. Perinatal infections. Amsterdam: Excerpta Medica, 1978.

5 Cooke CW, Mallock JA, Wurzel H, Oski F, Wallach EE. Fetal and maternal outcome in asymptomatic bacilluria of pregnancy. Obstet Gynecol 1970;36:840-4.

6 Brumfitt W. The effects of bacteriuria of pregnancy on maternal and fetal health. Kidney Int 1975;8(suppl):113-9.

1975;8(suppl):113-9.
7 Czerwinski AW, Wilkerson RG, Merrill JA, Braden B, Colmore JP. Further evaluation of the Griess test to detect significant bacteriuria. Am J Obstet Gynecol 1971;110:677-81.

8 Kunin CM, DeGroot JE. Self screening for significant bacteriuria. FAMA 1975;231:1349-53.

9 Isenberg HD, Washington JA, Ballows A, Soonerwirth AC. Collection, handling and processing of specimens. In: Lennette EH, Ballows A, Hausler WJ, Truant JP, eds. Manual of clinical microbiology. Washington DC: American Society for Microbiology, 1980.

10 Fletcher RH, Fletcher SW, Wagner JA. Clinical epidemiology: the essentials. Baltimore: Williams and Wilkins, 1982.

11 Wilson JMG, Jugner G. Principles and practice of screening for disease. Public Health Pap 1968;34:1-163.

(Accepted 10 October 1987) 